\title{
EVALUATING ACCURACY OF FAULT LOCALIZATION WHEN MONITORING CONDITION OF LARGE STRUCTURES BY ACOUSTIC METHOD
}

\author{
Jevgenijs Prostaks ${ }^{1}$, Margarita Urbaha ${ }^{2}$ \\ ${ }^{1}$ AS “AirBaltic Corporation”, Latvia; ${ }^{2}$ Riga Technical University, Latvia \\ jevgenijs.prostaks@gmail.com, urbaha.margarita@gmail.com
}

\begin{abstract}
This work proposes a method of large structure monitoring based on the measurement and analysis of acoustic emission (AE) signals. For fault localization, it is proposed to use a parameter of propagation velocity of AE signals recorded by an extensive network of highly-sensitive piezoelectric sensors. The results of theoretical calculations and experimental studies involving the use of modern AE measurement tools are presented.
\end{abstract}

Keywords: diagnostics, acoustic, emission, sensors, fault, localization.

\section{Introduction}

Modern machines, mechanisms, vehicles and construction projects are distinguished by high reliability and durability. However, the appearance of various failure-causing (leading to destruction, operability loss) faults in their structure is one of the most important problems during the whole life cycle of a product. One of the solutions to this problem is continuous or periodic monitoring of the condition of structures at the stages of production, repair and operation by using various methods of non-destructive testing and technical diagnostics [1-3]. At the same time, it is particularly complex to monitor large structures of machines, engineering systems and constructions [3-5].

Monitoring of the condition of large structures with the help of traditional monitoring methods (visual optical, ultrasonic, vortex-current, etc.) [6] is either impossible or inefficient due to excessive effort. First and foremost, this is related to the necessity of scanning the whole surface (area) to be monitored. The application of the Acoustic Emission (AE) method for diagnostics makes it possible to monitor structural elements with the help of AE transducers (AET) fixed on the surface thus making scanning unnecessary [3;7-10]. A reduction in the amount of fault detection work is an advantage of this integrated monitoring method.

However, there arises a problem of accurate fault localization (determining coordinates) in large complex structures $[3 ; 5 ; 11 ; 12]$.

For fault localization, this article proposes to use a parameter of propagation velocity of $\mathrm{AE}$ signals recorded by an extensive network of highly-sensitive piezoelectric sensors. The attempt of a solution of the problem of the research offered in the present article is undertaken by many authors and is presented in patents [13-16]. However, the proposed solutions differ in high complexity and rather low accuracy. The scientific novelty of this research is confirmed also by the patent offered by one of the authors of the present article M. Urbaha [17]. In the present article further development of a solution of the problem of exact determination of coordinates of defects in designs of difficult configurations and the big sizes is offered. The results of theoretical calculations and experimental studies involving the use of modern $\mathrm{AE}$ measurement tools are presented.

\section{Methods and Equipment}

During the research the following equipment was used - a multi-channel AE control equipment "Vallen Systeme" [18].

The following settings were used: range of the received AE signals - from 5 to $1000 \mathrm{kHz}$, threshold $-30 \mathrm{~dB}$, internal preamplifiers $-26 \mathrm{~dB}$, frequency of sampling -2 MSPS.

The experimental studies have been carried out using a flat sample made of sheet steel with a geometry of $0.8 \times 0.5 \times 0.002 \mathrm{~m}$. The experiments involved the use of an acoustic array consisting of 3 AET. The diagram of the acoustic array and AET position are presented in Fig. 1. AET position coordinates are presented in Table 1. The original AE signal (from the source) was simulated with the help of Nelson's method using a pencil lead $[11 ; 12]$ at a point with coordinates $(0.15 ; 0.25)$. The error in determining the coordinates of $\mathrm{AE}$ source was evaluated based on the results of measurements. The experimental values of differences in acoustic pulse propagation paths to three AET forming the acoustic array were used to locate the source of discrete $\mathrm{AE}$ on the plane. 
In order to increase the accuracy and reliability of statistical data of these experiments for each of the possible combinations of sensor interaction at least 12 measurements were performed.

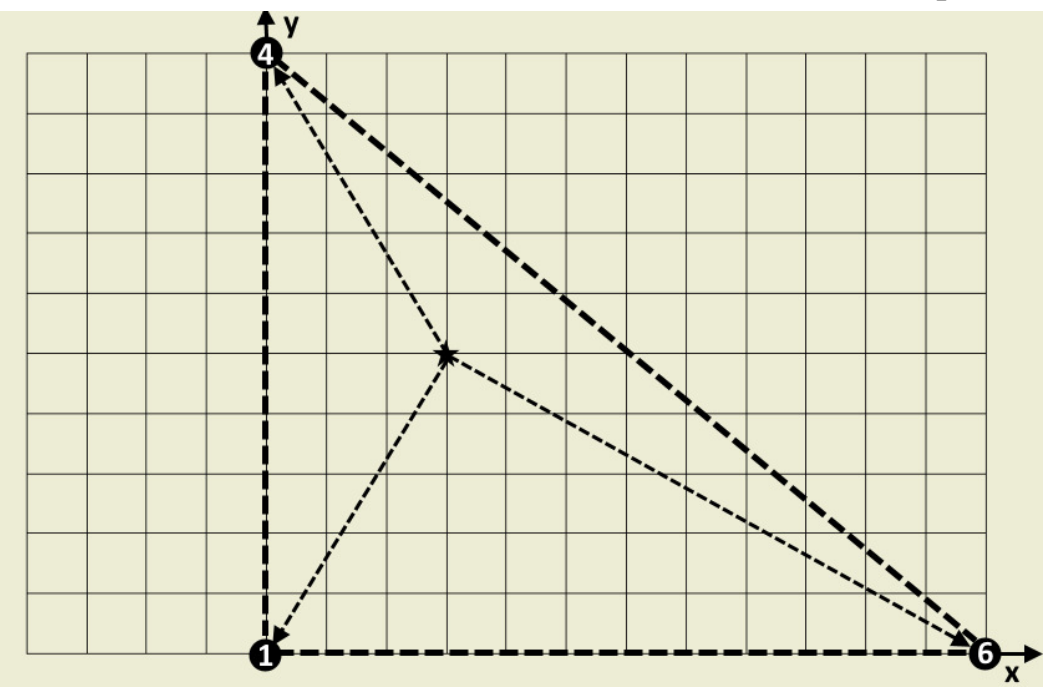

Fig. 1. Model of acoustic array in Cartesian coordinate system $x-y: 1,4,6$ - AET numbers

Table 1

AET coordinates

\begin{tabular}{|c|c|c|}
\hline No. & $\boldsymbol{s , ~ m}$ & $\boldsymbol{y}, \mathbf{m}$ \\
\hline AET1 & 0 & 0 \\
\hline AET4 & 0 & 0.5 \\
\hline AET6 & 0.6 & 0 \\
\hline
\end{tabular}

To evaluate the error of the indirect measurement of AE source coordinates Formula 1 was used:

$$
\Delta r_{i}=\sqrt{\left(\frac{\partial r_{i}\left(L_{41}, L_{46}, r_{1}, r_{4}, r_{6}\right)}{\partial L_{41}}\right)^{2}\left(\Delta L_{41}\right)^{2}+\left(\frac{\partial r_{i}\left(L_{41}, L_{46}, r_{1}, r_{2}, r_{3}\right)}{\partial L_{46}}\right)^{2}\left(\Delta L_{46}\right)^{2}},
$$

where $\Delta L_{41}, \Delta L_{46}$ - error in the calculation of the difference of wave paths from the AE source to AET4 and AET1, to AET4 and AET6, m, respectively;

$i=1,2$ - number of the coordinate vector component of the source on the plane;

$r_{1}, r_{4}, r_{6}-$ AET vector radiuses, $\mathrm{m}$;

$L_{41}, L_{46}$ - difference of the distances from the source to AET4 and AET1, to AET4 and AET6, m, respectively.

The difference of propagation paths to the two AET was determined based on the measured time of the AE pulse arrival (Formulas 2 and 3).

$$
\begin{aligned}
& L_{41}=C\left(t_{1}-t_{4}\right), \\
& L_{46}=C\left(t_{6}-t_{4}\right),
\end{aligned}
$$

where $C$ - group velocity of AE pulse propagation, $\mathrm{m} \cdot \mathrm{s}^{-1}$;

$t_{1}, t_{4}, t_{6}-$ time of pulse arrival at 1,4 and 6 AET, s.

The error $\Delta L 41(\Delta L 14)$ in the calculation of the difference of wave paths from the AE source to AET4 and AET1 (of pulse arrival time (time delay)) was calculated according to Formula 4:

$$
\Delta L_{14}=C\left(\Delta \mathrm{t}_{1}-\Delta t_{4}\right) \text {, }
$$

where $\Delta t_{1}, \Delta t_{4}-$ error of determining the time of AE pulse start, $\mathrm{s}$. 


\section{Results and Discussion}

To evaluate the errors of $\Delta t_{1}$ and $\Delta t_{4}$ values, let us analyze the regularities of acoustic pulse propagation in the object being monitored.

Through the obtained experimental data it was possible to determine the numerical values of proportionality coefficients $k_{f}$ between the duration of the pulse leading edge and the time of its propagation (Formulas 5 and 6). In equations (5) and (6) the duration of the leading edge of arriving pulses $t_{f}$ is known; the duration was obtained through calculations using the $\mathrm{AE}$ system program "Vallen Systeme".

$$
\begin{aligned}
& k_{f 4}=\frac{t_{f 4}}{t}, \\
& k_{f 1}=\frac{t_{f 1}}{t},
\end{aligned}
$$

where $t_{f}$ - duration of pulse leading edge, s;

$t$ - time of pulse propagation, $\mathrm{s}$.

The numerical values of the proportionality coefficients are: $k_{4 f}=0.958 ; k_{1 f=} 1.003$. The time of pulse propagation from the AE source to the AET was calculated by Formulas 7 and 8 .

$$
\begin{aligned}
& t_{4}=\frac{S_{4}}{C}, \\
& t_{1}=\frac{S_{1}}{C},
\end{aligned}
$$

where $S$ - distance from the AE source to the AET, m;

$C$ - group velocity of AE pulse propagation, $\mathrm{m} \cdot \mathrm{s}^{-1}$.

The values of the time of pulse propagation from the AE source to the AET are: $t_{4}=5.47249 \mathrm{E}-05 \mathrm{~s} ; t_{1}=5.47249 \mathrm{E}-05 \mathrm{~s}$.

Measuring the time of pulse arrival from the AE source to the AET is reduced to the task of separating the start of a pulse against the continuous noise background. The threshold method of determining the time of pulse start is based on detecting the moment when an electrical AE signal exceeds the critical value (threshold level). The error of the pulse start time can be determined by Formulas 9 and 10:

$$
\begin{aligned}
\Delta t_{4} & =k t_{f 4} \frac{U_{n}}{U_{\text {max }}}, \\
\Delta t_{1} & =k t_{f 1} \frac{U_{n}}{U_{\text {max }}},
\end{aligned}
$$

where $U_{n}-$ mean square deviation of noise, $\mathrm{mV}$;

$U_{\max }$ - pulse amplitude, $\mathrm{mV}$;

$t_{f}$ - duration of pulse leading edge, s;

$k$ - non-dimensional coefficient determined by the algorithm for calculating the pulse start time.

The values of the errors of the pulse start time are: $\Delta t_{4}=\Delta t_{1}=5.47249 \mathrm{E}-05 \mathrm{~s}$. As a result, we can obtain an error of the AE pulse arrival time, taking all factors into account:

$$
\begin{aligned}
& \Delta t_{4}=k t_{f 4} \frac{U_{n}}{U_{\text {max }}} \cdot k_{f}, \\
& \Delta t_{1}=k t_{f 1} \frac{U_{n}}{U_{\text {max }}} \cdot k_{f},
\end{aligned}
$$


where $k$-non-dimensional coefficient;

$t_{f}$ - duration of pulse leading edge, s;

$U_{n}$ - mean square deviation of noise, $\mathrm{mV}$;

$U_{\max }$ - pulse amplitude, $\mathrm{mV}$;

$k_{f}$ - proportionality coefficient.

Taking all factors into account, the values of the errors of the $\mathrm{AE}$ pulse arrival time are: $\Delta t_{4}=4.7121 \mathrm{E}-10 \mathrm{~s} ; \Delta t_{1}=7.2257 \mathrm{E}-10 \mathrm{~s}$. Substituting Formulas 11 and 12 for 4 , it is possible to get:

$$
\Delta L_{41}=C\left(k t_{f 4} \frac{t_{f 4}}{t_{4}} \frac{U_{4 n}}{U_{4 \max }}-k t_{f 1} \frac{t_{f 1}}{t_{1}} \frac{U_{1 n}}{U_{1 \max }}\right),
$$

where $t_{1}, t_{4}$ - time of pulse propagation from the AE source to the AET1 and AET4, s;

$k$ - non-dimensional coefficient;

$t_{f}$ - duration of pulse leading edge, s;

$U_{n}$ - mean square deviation of noise, $\mathrm{mV}$;

$U_{\max }-$ pulse amplitude, $\mathrm{mV}$.

The obtained value of the error of the pulse arrival time (time delay) is $\Delta L_{41}=-1.3391 \mathrm{E}-6 \mathrm{~m}$.

This means that in this case, under the influence of all factors, the total error of propagation between AET4 and AET1 will be equal to approximately $1 \mu \mathrm{m}$.

Similar calculations were carried out for AET1 and AET6 pair. The total error of propagation between AET1 and AET6 $\Delta L_{61}$ is equal to $0.004 \mu \mathrm{m}$.

Such an insignificant error is explained by the small dimensions of piezoelectric array (up to $5 \mathrm{~m}$ ). The coefficient $k$ also plays its part in the obtained results. In our calculations this coefficient was approximately taken as 1 .

The sensitivity ratio of channels 1 and 4 , which is 88.125 , was also experimentally determined: $87.325, \mathrm{~dB}$.

If significant external sources are absent, the noise level is determined by the electrical noises of the equipment. The increase of the signal-to-noise ratio leads to error reduction; therefore, we will evaluate the minimum value of the coefficient $K_{s n}$, using the value of the AE system discrimination threshold $\left(U_{0}\right)$ and the inherent noise level of the equipment $\left(U_{n}\right)$ :

$$
K_{s n}=\frac{U_{0}}{U_{n}},
$$

where $U_{0}$ - value of $\mathrm{AE}$ system discrimination level, $\mathrm{mV}$;

$U_{n}$ - equipment noise level, $\mathrm{mV}$.

For the equipment being used, the noise level is equal to $29 \mathrm{~dB}$ and the value of the discrimination threshold is equal to $35 \mathrm{~dB}$. The minimum value of the coefficient $K_{s n}$ is 1.2.

The ratio of acoustic pulse amplitudes at AET4 and AET1 is determined by the dependence of wave attenuation:

$$
K_{A}=\frac{U_{4 \max }}{U_{1 \max }}=\sqrt{\frac{l_{4}}{l_{1}} e^{-\delta\left(l_{4}-l_{1}\right)}},
$$

where $l_{1}, l_{4}$ - path of AE signal propagation from the source to AET1 and AET4, m;

$\Delta$ - attenuation coefficient;

$U_{\max }$ - pulse amplitude, $\mathrm{mV}$.

The obtained ratio of acoustic pulse amplitudes at AET4 and AET1 is $K_{A}=1.43$.

It has been experimentally proved that wave attenuation for acoustic arrays, the linear dimensions of which do not exceed $5 \mathrm{~m}$, may not be taken into consideration [2].

The final form of the error in measuring the difference of acoustic wave propagation paths from the source to AET1 and AET4 can be calculated by formulas: 


$$
\begin{aligned}
& \Delta L_{41}=\frac{t_{f 4}}{t} l_{4} \frac{k}{K_{s n}}\left(\sqrt{\frac{l_{4}}{l_{1}}} K_{s}-1\right) \\
& \Delta L_{61}=\frac{t_{f 6}}{t} l_{1} \frac{k}{K_{s n}}\left(\sqrt{\frac{l_{6}}{l_{1}}} K_{s}-1\right),
\end{aligned}
$$

where $l_{1}, l_{4}, l_{6}$ - paths of AE signal propagation from the source to AET1, AET4 and AET6, m; $t_{f}-$ duration of pulse leading edge, $\mathrm{s}$;

$t$ - time of pulse propagation, $\mathrm{s}$;

$k$ - non-dimensional coefficient;

$K_{s}$ - sensitivity ratio of channels 4 and 1 ;

$K_{s n}$ - signal-to-noise ratio of channel 4 of AE system.

The values of errors in measuring the difference of acoustic wave propagation paths from the source to AET1 and AET4 respectively are $\Delta L_{41}=0.001 \mathrm{~m} ; \Delta L_{61}=-0.03 \mathrm{~m}$.

From the analysis of Formulas 16 and 17 it follows that the error in determining the differences of acoustic wave propagation paths is determined by the signal-to-noise ratio at the first receiving AET by the ratio of AE channel sensitivities, propagation time, ultrasonic beam attenuation and divergence, as well as by acoustic wave velocity dispersion in the object being monitored.

Then let us evaluate the dependence of the error of acoustic wave propagation path difference on the location of the AE source in the piezoelectric array. Let us simulate AE signals in points located on a horizontal line, from right to left (Fig. 2). The coordinates of AET are presented in Table 2 and the coordinates of AE sources are shown in Table 3.

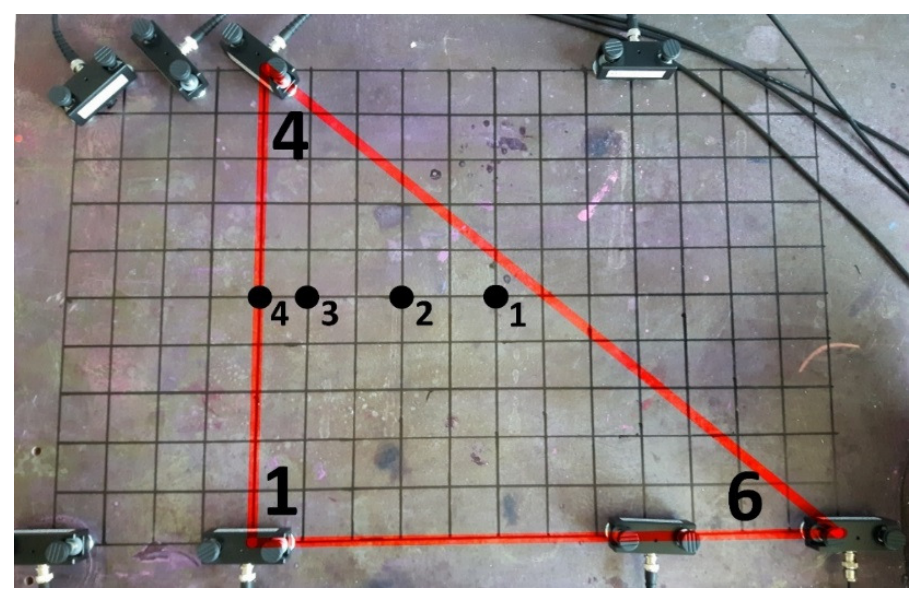

Fig. 2. Diagram of piezoelectric array and AE source location

Table 2

AET coordinates

\begin{tabular}{|c|c|c|}
\hline AET & $\boldsymbol{x}, \mathbf{m}$ & $\boldsymbol{y}, \mathbf{m}$ \\
\hline 1 & 0 & 0 \\
\hline 4 & 0 & 0.5 \\
\hline 6 & 0.6 & 0 \\
\hline
\end{tabular}

Coordinates of AE sources

Table 3

\begin{tabular}{|c|c|c|}
\hline AE source & $\boldsymbol{x}, \mathbf{m}$ & $\boldsymbol{y}, \mathbf{m}$ \\
\hline 1 & 0.25 & 0.25 \\
\hline 2 & 0.15 & 0.25 \\
\hline 3 & 0.05 & 0.25 \\
\hline 4 & 0 & 0.25 \\
\hline
\end{tabular}


The errors of the difference of acoustic wave propagation paths are determined separately for each point according to the above-mentioned algorithm. The results of the calculations are presented in Table 4.

Table 4

\section{Values of the errors of acoustic wave propagation path difference}

\begin{tabular}{|c|c|c|}
\hline AE source & $\boldsymbol{\Delta L}_{\mathbf{4 1}}, \mathbf{m}$ & $\boldsymbol{\Delta}_{\mathbf{6 1}}, \mathbf{m}$ \\
\hline 1 & 0.00155 & 0.0168 \\
\hline 2 & 0.00128 & 0.031 \\
\hline 3 & 0.001 & 0.0407 \\
\hline 4 & 0.0011 & 0.0431 \\
\hline
\end{tabular}

From the calculations it follows that the error $\Delta L 41$ remains practically unchanged independently of the movement of the AE signal source along the horizontal line in the array. This is explained by the fact that at any point the AE source is equidistant from AET1 and AET4.

Considering the error $\Delta L 61$, we can see that its smallest value will be closer to the right edge of the array $\Delta L 61=0.0168 \mathrm{~m}$, when the distances from the AE source to AET6 and AET1 are almost equal. As the AE source moves to the left, along the horizontal line, the error of determining the coordinate $x$ increases and reaches its maximum value $\Delta L 61=0.0431 \mathrm{~m}$ at the left limit of the array.

Carrying out the AE monitoring of real objects, one dimension of the acoustic array is usually related to the width or height of the structure, while the other dimension is set based on the evaluation of the error in determining the coordinates of AE sources.

\section{Conclusions}

1. From the strategic point of view, the present paper is a basis for carrying out further scientific research in the field of diagnostics of big - sized difficult configuration constructions, such as bridges, building structures, aviation and space systems. In all these cases it is necessary to carry out a cluster, zonal, 3D or plane location.

2. An experimental evaluation of the accuracy of fault localization in large structures based on the acoustic emission method has been carried out.

3. The experimental studies have been carried out using a flat sample made of steel sheet. The original AE signal (from the source) was simulated with the help of the Nelson's method. The experimental values of differences in acoustic pulse propagation paths to three AET forming the acoustic array were used to locate the source of discrete AE on the plane.

4. It was found that an error in determining the coordinates of a fault depends on the signal-to-noise ratio of receiving sensors, time of ultrasonic signal propagation, ultrasonic beam attenuation and divergence, acoustic wave velocity dispersion in the object being monitored and the location of the $\mathrm{AE}$ source in the piezoelectric array.

\section{Acknowledgement}

This work has been supported by the European Regional Development Fund within the Activity 1.1.1.2 "Post-doctoral Research Aid" of the Specific Aid Objective 1.1.1 "To increase the research and innovative capacity of scientific institutions of Latvia and the ability to attract external financing, investing in human resources and infrastructure" of the Operational Programme "Growth and Employment" (No. 1.1.1.2/VIAA/1/16/176 "Multifunctional Nanostructured Coatings for Aircraft Structures (NANOCOAIRS)")

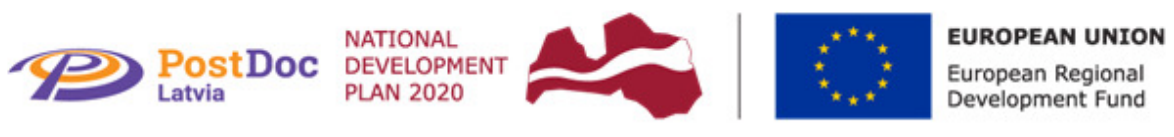

INVESTING IN YOUR FUTURE

\section{References}

[1] Lingelli A. Fatigue Crack Growth. Mechanics, Behavior and Prediction. New York, Nova Science Publishers Inc., 2009. 264 p. ISBN: 1606924761 
[2] Hasiotis T., Badogiannis E. \& Tsouvalis N.G. 2011. Application of ultrasonic C-scan techniques for tracing defects in laminated composite materials. Strojniski Vestnik/Journal of Mechanical Engineering, 57(3), pp.192-203.

[3] Pollock A.A. Acoustic Emission Inspection, Metals Handbook, 9th edition, Vol. 17, Materials Park, Ohio, ASM International, 1989. pp. 278-294.

[4] Urbahs A., Carjova K., Stelpa I., Fescuks J. Durability characteristics evaluation of low-voltage network: Reinforced concrete poles AES-ATEMA International Conference Series - Advances and Trends in Engineering Materials and their Applications, 2016-January, pp. 43-51.

[5] Baxter M.G. et al. Delta T source location for acoustic emission. Mechanical Systems and Signal Processing, 21(3), 2007. pp. 1512-1520.

[6] Urbach A., Banov M., Turko V., Feshchuk Y. Diagnostics of Fatigue Damage of Gas Turbine Engine Blades. - Journals of World Academy of Science, Engineering and Technology, WASET Issue 59 (part IX), 2011. pp. 906-911

[7] Elamin F., Glikes O., Gu F. and Ball A. The Analysis of Acoustic Emission Signals from the Cylinder Head of a Diesel Engine for Fault Detection. CM 2010 and MFPT 2010: The Seventh International Conference on Condition Monitoring and Machinery Failure Prevention Technologies, 22-24 June 2010, Stratford-upon-Avon, UK.

[8] Abdou W, Balodimos N, Reuben B. Acoustic Emission in Diesel Engines - Towards a Time Series Model for The Injection Process Proc. 30th European Conference on Acoustic Emission Testing \& 7th International Conference on Acoustic Emission, University of Granada, 2013. pp. 394-406.

[9] Bhavikatti S., Bhat M. \& Murthy C., 2011. Fatigue Crack Growth Monitoring in Ti-6Al-4V Alloy using Acoustic Emission Technique and Digital Image Correlation. Journal of Non-Destructive Evaluation, 9(4).

[10] Urbahs A., Banovs M., Carjova K., Turko V., Feshchuk J. Research of the micromechanics of composite materials with polymer matrix failure under static loading using the acoustic emission method. Aviation, 2017. 21 (1), pp. 9-16. DOI: 10.3846/16487788.2016.1264720.

[11] Urbahs A., Carjova K. Bolting Elements of Helicopter Fuselage and Tail Boom Joints Using Acoustic Emission Amplitude and Absolute Energy Criterion. In: Journal of Aerospace Engineering, American Society of Civil Engineers, 2019, ISSN (print): 0893-1321, ISSN (online): 1993-5529, Vol.32, Issue 3.

[12] Urbahs A., Carjova K., Fescuks J. Analysis of the results of acoustic emission diagnostics of a structure during helicopter fatigue tests. Aviation, 2017. 21 (2), pp.64-69. DOI: 10.3846/16487788.2017.1335231.

[13]Виноградов А.Ю., Костин В.И., Мерсон Д.Л. Способ определения координат источника акустической эмиссии. Патент №2498293. БИ№31 от 10.11.2013Г (Method of determining coordinates of signal sources of acoustic emission). (In Russian).

[14]Бырин В.Н., Косткин М.Д., Макшанов А.В. Способ акустоэмиссионного контроля изделий Патент №2141654, 20.11.1999 г. (Method of acoustic emission control of products). (In Russian).

[15] Алякритский А. Л., Терентьев Д. А., Ростовцев М. Ю. Способ определения геометрических координат преобразователей акустической эмиссии. Патент №2330277, 27.07.2008 г. (Method of determination of geometrical coordinates of converters of acoustic emission) (In Russian).

[16]Банов М.Д., Урбах А.И., Тухтиев Р. А., Малышев А.Ю. Способ определения координат источников сигналов акустической эмиссии. // А.C. SU 1516964 А1. / опубл. в БU N 39, 1989) (Method of determining coordinates of signal sources of acoustic emission). (In Russian).

[17] Urbahs A., Banovs M., Urbaha M., Carjova K., Feščuks J. "Konstrukciju skrūvju un kniežu savienojumu ultraskaņas kontroles paņemiens". Latvijas patents LV 14971 B, 20.04.2015.g. (pieteikuma numurs: P-13-170, iesniegšanas datums: 20.08.2013).

[18] Vallen H. Acoustic emission testing fundamentals, equipment, applications. Informative booklets for non-destructive testing, NDT compact and understandable. Wuppertal (Germany). Castell Publication Inc., 2006. ISBN: 3-934255-26-4. 